\title{
Assessment of the Sustainability of Water Resources Management: A Critical Review of the City Blueprint Approach
}

\author{
Steven H. A. Koop ${ }^{1,2}$ • Cornelis J. van Leeuwen ${ }^{1,2}$
}

Received: 21 April 2015 / Accepted: 10 September 2015 /

Published online: 23 September 2015

(C) The Author(s) 2015. This article is published with open access at Springerlink.com

\begin{abstract}
Climate change, urbanization and water pollution cause adverse effects and rehabilitation costs that may exceed the carrying capacity of cities. Currently, there is no internationally standardized indicator framework for urban Integrated Water Resources Management (IWRM). The City Blueprint ${ }^{\circledR}$ is a first attempt and aims to enhance the transition towards water-wise cities by city-to-city learning. This paper provides a three step revision of the City Blueprint Framework (CBF) based on data of 45 municipalities and regions in 27 countries: (1) A distinction has been made between trends and pressures (on which urban IWRM has a negligible influence) and IWRM performances. Therefore, a separate trends and pressures framework has been developed; (2) Only the purely performance-oriented indicators have been selected from the CBF. Furthermore, the indicator accuracy and boundaries have been re-assessed, and new indicators have been added; (3) By analyzing correlations and variances, the performance-oriented indicators have been rearranged in order to establish a proportional contribution of all indicators and categories to the overall score, i.e., the Blue City Index ${ }^{\circledR}$. In conclusion, six indicators have been removed because of insufficient accuracy, overlap or lack of focus on IWRM. Seven indicators have been added, i.e., secondary and tertiary wastewater treatment, operation cost recovery, green space and three indicators concerning solid waste treatment. The geometric aggregation method has been selected because it emphasizes the need to improve the lowest scoring indicators. In conclusion, the improved $\mathrm{CBF}$ is more performance-oriented and therefore more suitable to assist cities in their transition towards water-wise cities.
\end{abstract}

Cornelis J. van Leeuwen

Kees.van.Leeuwen@kwrwater.nl

1 KWR Watercycle Research Institute, Groningenhaven 7, Nieuwegein 3433 PE, The Netherlands

2 Copernicus Institute for Sustainable Development and Innovation, Utrecht University, Heidelberglaan 2, Utrecht 3584 CS, The Netherlands 
Keywords Urban water management $\cdot$ Climate change $\cdot$ Sustainability indicators $\cdot$ Blue City Index ${ }^{\circledR}$. EIP Water

\section{Urban Water Challenges}

Rapid urbanization and climate change pose increasing pressures on Integrated Water Resources Management (IWRM), especially in cities (OECD 2015). In 2014, about 4 billion people lived in cities, mostly situated along coasts and major rivers (accounting for $54 \%$ of the world's population). IWRM becomes even more challenging as the global urban population is estimated to increase with 2.5 billion people by 2050 (UN 2014).

Climate change amplifies urban water vulnerabilities such as flooding, heat stress, water scarcity and water pollution. Sea level rise and increased river discharges pose a projected $15 \%$ of the global population at risk of flooding. This is mainly in cities including almost all worlds' megacities (Ligtvoet et al. 2014). Also, extreme rainfall and heat waves will become more severe due to global warming (Jongman et al. 2014). As urban surfaces are often largely sealed and lack green areas, the impact of drainage flooding and Urban Heat Islands (UHI) are even more exacerbated (Shuster et al. 2005; Gill et al. 2007). Water withdrawals are estimated to increase by $50 \%$ in developing countries and by $18 \%$ in developed countries by 2025 (WWDR 2006). This increased water demand will lead to an estimated $40 \%$ fresh water shortage by 2030 (2030 WRG 2009). Climate change will exacerbate these fresh water shortages (Iglesias et al. 2007) and amplify the spread of water-borne diseases (IPCC 2013). Pollution from combined sewer overflows and stormwater runoff will rise due to climate induced increase in extreme rainfall events (Nilsen et al. 2011). Rapid urbanization poses extra stresses, for example, wastewater treatment in Asia and Africa is already sparse, while nutrient emissions are projected to double or triple within 40 years. This will strongly enhance eutrophication, biodiversity loss, threaten drinking water, fisheries, aquaculture, and tourism (Ligtvoet et al. 2014). Moreover, cities produce massive amounts of solid waste, in particular plastics. Worldwide 280 million tons of plastics are produced annually (Sigler 2014). These plastics photodegrade into small particles that affect marine ecosystems (Derraik 2002).

The prospect of increased urban flooding, heat stress, water scarcity and pollution emphasizes the need for adaptive and reliable urban water infrastructures (Short et al. 2012). However, water infrastructures are often old and require refurbishment to meet current standards, whereas standards to withstand future conditions of increased storm events and urbanization are often not accounted for (OECD 2015). An estimated US\$ 41 trillion $\left(41 \times 10^{12}\right)$ is needed to refurbish the urban infrastructure in the period 2005-2030. Over $50 \%$ will be needed to refurbish the water systems (UNEP 2013). This is roughly $60 \%$ more than is spent on infrastructure in the same period until now (McKinsey 2013). In developed countries water infrastructure investments amount to $1 \%$ of the GDP every year. For developing countries this is even more substantial, i.e., about $3.5 \%$ with extremes up to $6 \%$ or more (Cashman and Ashley 2008). The costs of climate change related damages are expected to be large. In Europe this is estimated to be $€ 190$ billion by 2080 (JRC 2014), especially flood 
damage is predicted to increase five-fold by 2050 (Jongman et al. 2014). Recent extreme weather events resulted in much damage. For example, in 2011 in Copenhagen a storm event caused a lot of damage of nearly $€ 1$ billion (Leonardsen 2012). In the USA, hurricane Sandy (2012) caused 117 deaths and costs US\$ 19 billion including US\$ 2.6 billion to repair New York's drinking and wastewater infrastructure (Johnson 2013). These alarming events demonstrate the climate vulnerability of cities and the urgency to improve urban IWRM.

\section{The City Blueprint}

Approximately $80 \%$ of the world's GDP is produced, and $75 \%$ of the global energy and material flows are consumed in cities (UNEP 2013). This makes cities the major contributors of economic growth but also the major sources of environmental pressures. It also implies that cities have the highest potential to reduce these pressures. Urban water management is often locked-in to the large-scale, centralized infrastructure approaches limiting the adoption of more flexible and resilient technologies and approaches such as fit-for-purpose water use, nutrient and energy recovery from wastewater, and blue-green infrastructures (Brown et al. 2011). Hence, the main objective of the City Blueprint ${ }^{\circledR}$ action is to create awareness among decision makers and resource managers. It may help them envisioning, developing and implementing stepwise measures to transform towards water-wise or water sensitive cities (EC 2015). Improving the implementation capacities of cities by sharing information can be described as city-to-city learning. The first step in the strategic planning process is that stakeholders are identified and information is provided for a baseline assessment. Hereafter, long-term goals and priorities are set resulting in follow-up actions leading to measures that promote sustainable IWRM (Philip et al. 2011; Van Leeuwen and Sjerps 2015). The City Blueprint Framework (CBF) aims to be the first step in strategic planning and consists of 24 indicators divided over eight broad categories, i.e., 1) Water security, 2) Water quality, 3) Drinking water, 4) Sanitation, 5) Infrastructure, 6) Climate robustness, 7) Biodiversity and attractiveness, and 8) Governance. The output is a spider diagram and a Blue City Index ${ }^{\circledR}(\mathrm{BCI})$. The BCI is the arithmetic mean of the 24 indicators. The methodology and its application have been published in this journal (Van Leeuwen et al. 2012; Van Leeuwen 2013) and a detailed description of the calculation methods is provided in the City Blueprint questionnaire available on the website of the European Innovation Partnership on Water (EC 2015).

This paper provides a critical revision of the CBF, based on the learning experiences obtained during the assessments in 45 cities in 27 countries. The aim of this revision is to:

- Provide a clear separation between indicators describing urban trends and pressures (on which local water managers have a negligible influence, e.g., current climatic conditions, demographic chances etc.) and indicators measuring IWRM performance in cities. The improved performance framework (CBF) will be more adequate in showing the potential 
for improvements and enhances city-to-city learning because emphasizes the city's own IWRM performance.

- Develop a separate framework describing the most important trends and pressures that may limit IWRM or, on the contrary, poses opportunity windows. This supplementary framework is key in providing context and may assist in the setting of priorities.

- Include solid waste indicators as important urban performers to decrease water pollution.

- Update existing indicators by including new developments in data accuracy and availability.

- Design a coherent framework in which indicators and categories make a balanced contribution to the overall score, i.e., the BCI.

- Select an aggregation method that penalizes unbalanced indicator scores in order to express the urgency to improve the lowest scoring indicators.

- Make sure that the indicator results are easy to understand, timely and relevant, and useful for the end-users, i.e., policy makers, decision makers, water managers and citizens in general.

\section{Methodology}

The application of the CBF followed a learning by doing approach. Based on constructive feedback from stakeholders, we have performed a detailed revision of the indicator choice and framework, together with a revision of the indicator scaling and aggregation method (Koop and Van Leeuwen 2015b). The process is summarized in Fig. 1 and is based on data of 45

\section{Inadequacies $\quad$ Revisions Application}

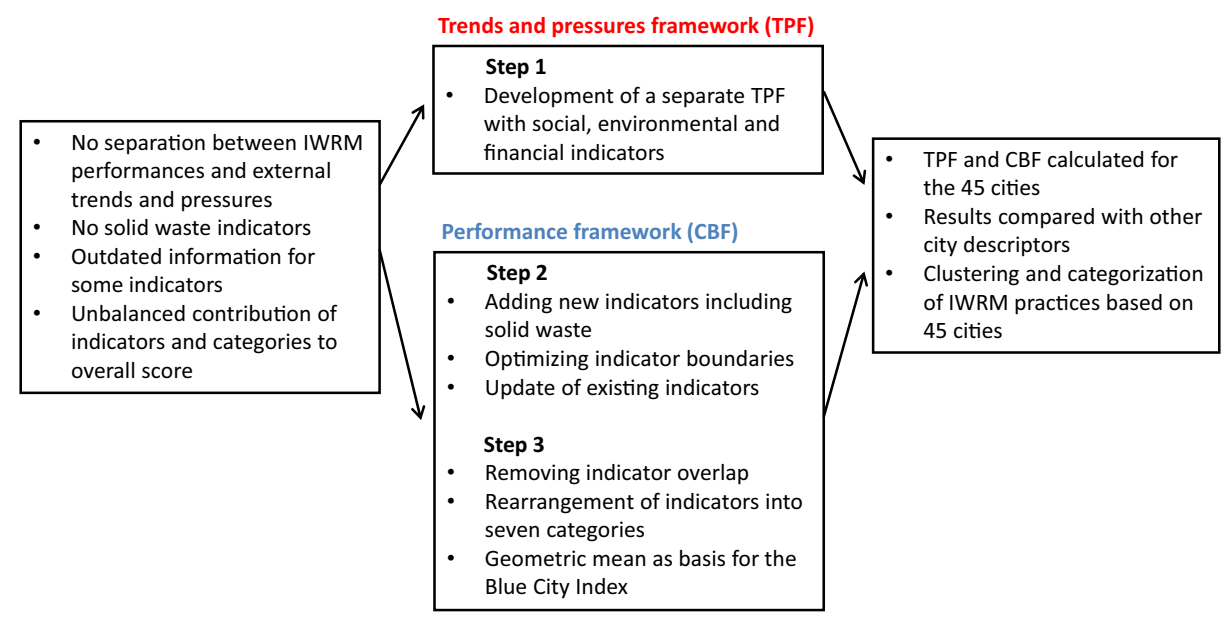

Fig. 1 Flow chart of the City Blueprint revision described in this paper using data of 45 cities divided over 27 countries. The applications of the Trends and Pressure Framework (TPF) and Performance framework (CBF) have been published in this journal (Koop and Van Leeuwen 2015a) 
municipalities and regions, mainly in Europe (Koop and Van Leeuwen 2015a). In the rest of this paper these municipalities, regions and Malta will be referred to as cities. This review consists of three consecutive steps:

Step 1 Development of the Trends and Pressure Framework (TPF).

Step 2 Improvements of the City Blueprint indicators.

Step 3 Indicator rearrangements and aggregation methods.

The application of the revised CBF and new TPF, the clustering and categorization of cities' IWRM performances, as well as comparisons with other city descriptors, have been published separately in this journal (Koop and Van Leeuwen 2015a).

\subsection{Step 1: Development of the Trends and Pressures Framework}

Every city has its own social, financial and environmental setting in which water managers have to operate. In order to promote city-to-city learning, it is essential to solely measure urban water management performances. For example, a city situated in an arid area may not necessarily experience water stress due to overconsumption, but simply due to the low natural availability of fresh water. In this case, water consumption or the use of water saving techniques are performance indicators, whereas the natural availability of fresh water is a descriptive indicator belonging to the TPF. A more performance-oriented set of indicators (CBF) is more adequate in showing the potential for improvements and sharing of knowledge, experiences and best practices between cities. A separate TPF may provide the context to obtain insight in the limitations and windows of opportunities for urban IWRM. Therefore, the first step in this review was the development of the TPF with the aim to provide an overview of the most important social, environmental and financial characteristics affecting urban IWRM.

\subsection{Step 2: Improvements of the City Blueprint Indicators}

All indicators of the CBF have been critically assessed on data reliability, scoring method and whether the used data are time-series in order to ensure that the indicators are up-to-date. At the same time new indicators are proposed to replace indicators with data problems. Also boundary issues are reviewed in order to adjust extreme indicator variances. Alternative scaling methods for a few indicators with sufficiently large data sets $(n>100)$ are proposed as well. Only performance-oriented indicators have been selected in this step.

\subsection{Step 3: Indicator Rearrangements and Aggregation Method}

Finally, the revised performance-oriented indicators have been rearranged to arrive at a more coherent framework. The aim was to obtain intra-category correlations (correlations between indicators of the same category) that were higher than the inter-category correlations (correlations of the indicators belonging to different categories). Hence, high correlations between indicators suggest that these indicators should be united into 
one category. Finally, it is aimed to equalize the number of indicators per category, to make sure that all categories equally contribute to the BCI. Furthermore, an aggregation method has been selected that penalizes unbalanced scores in order to emphasize the need to improve the lowest indicator scores.

\section{Results}

\subsection{Step 1: Development of the Trends and Pressures Framework}

Because the regenerative capacity and renewable resources on earth are limited (Hoekstra and Wiedman 2014), environmental pressures of cities need to be reduced provided that adequate living standards are maintained (Mori and Yamashita 2015). Hence, an equal number and weighing of indicators for social, environmental and financial classes has been strived for. Each indicator has been scaled from 0 to 4 points, where a higher score represents a higher urban pressure or concern. The following ordinal classes, expressed as 'degree of concern', have been used: 0-0.5 points (no concern), 0.5-1.5 (little concern), 1.5-2.5 (medium concern), 2.5-3.5 (concern), and 3.5-4 (great concern). In this way, a TPF is provided that depicts the most relevant topics that either hamper sustainable IWRM or, on the contrary, pose opportunity windows. Examples for three cities are shown in Section 4.4. For the social and financial categories, four well-known descriptive indicators have been selected, that are widely used to describe urban pressures. The environmental category is focussed on urban water and climate issues, i.e., flooding, water scarcity and heat risk (EEA 2012). Water quality is also included because cities are often situated at rivers and in deltas that receive pollution from upstream activities. Table 1 describes the scaling method and data sources of the indicators and sub-indicators that are proposed. Most of these indicators are scaled according to existing scaling methods. Furthermore, sub-indicator 5.4 (Land subsidence) and 6.3 (Salinization and seawater intrusion) are scaled according to an ordinal self-assessment.

For seven indicators and sub-indicators we have proposed a scoring method as no international standards are available. The scores are determined using the ranking of the city amongst all available country scores (Fig. 2). The rankings are linearly standardized on a scale from 0 to 4 points (y-axis Fig. 2). Subsequently, an equation has been selected that best fits this ranking (lowest correlation coefficient: $\mathrm{r}=0.97$; Table 1 ). Next, these equations are applied in order to determine the indicator scores for each city. The numbers are rounded and scores of 3 or 4 points are marked in red and communicated to the stakeholders because they are considered as a concern or great concern (see Table 3 in Section 4.4). These scores are not normative but only provide an indication of the urban pressures. Finally, the Trends and Pressure Index (TPI; the arithmetic mean of all twelve TPF indicators) can be calculated for each city.

\subsection{Step 2: Improvements of the City Blueprint Indicators}

\subsubsection{The Use of Wastewater Treatment as Indicator for Surface Water Quality}

Baseline assessments of IWRM in cities should preferably include surface water quality and biodiversity. Unfortunately, this appears problematic as a result of a lack of local data and 


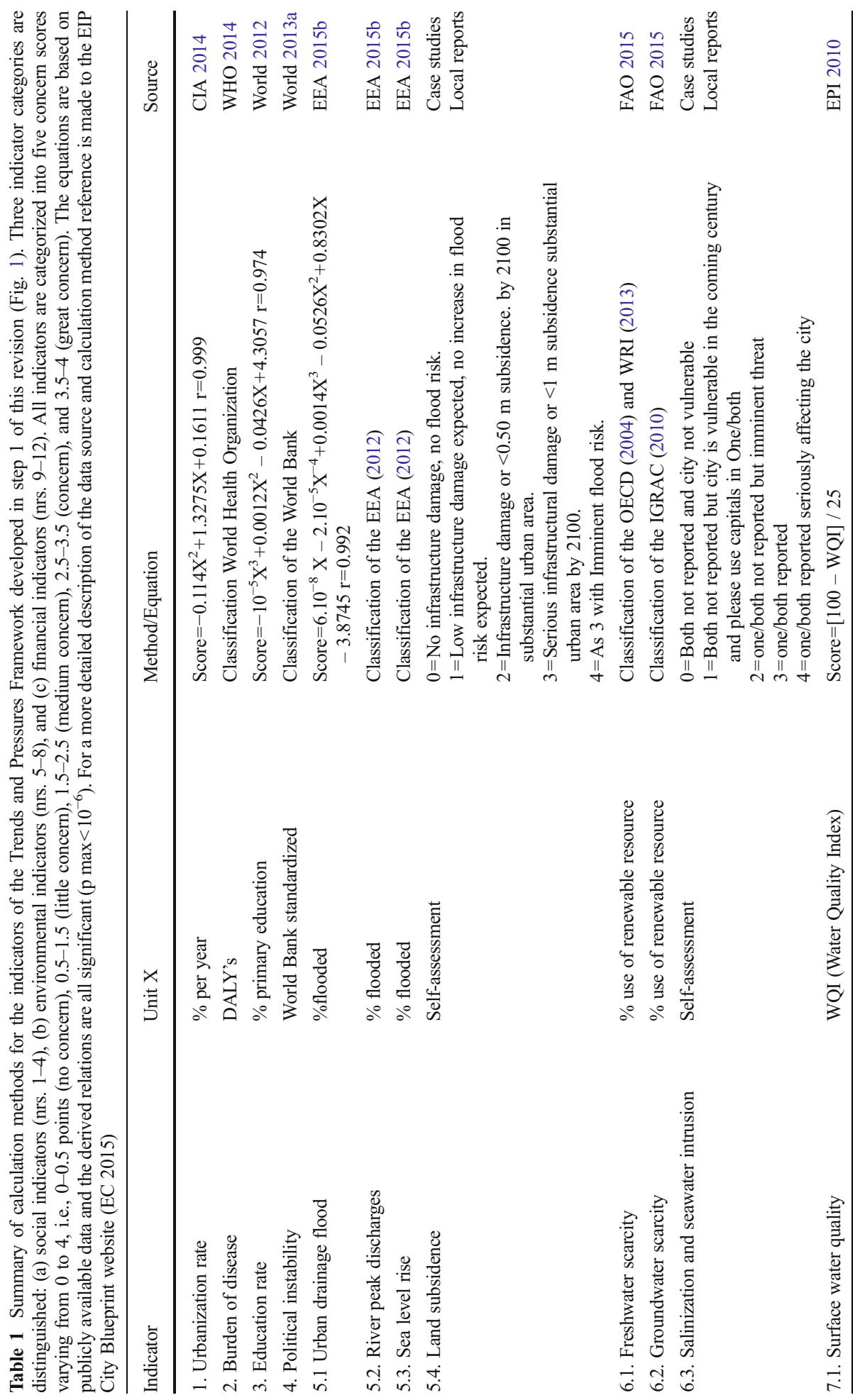




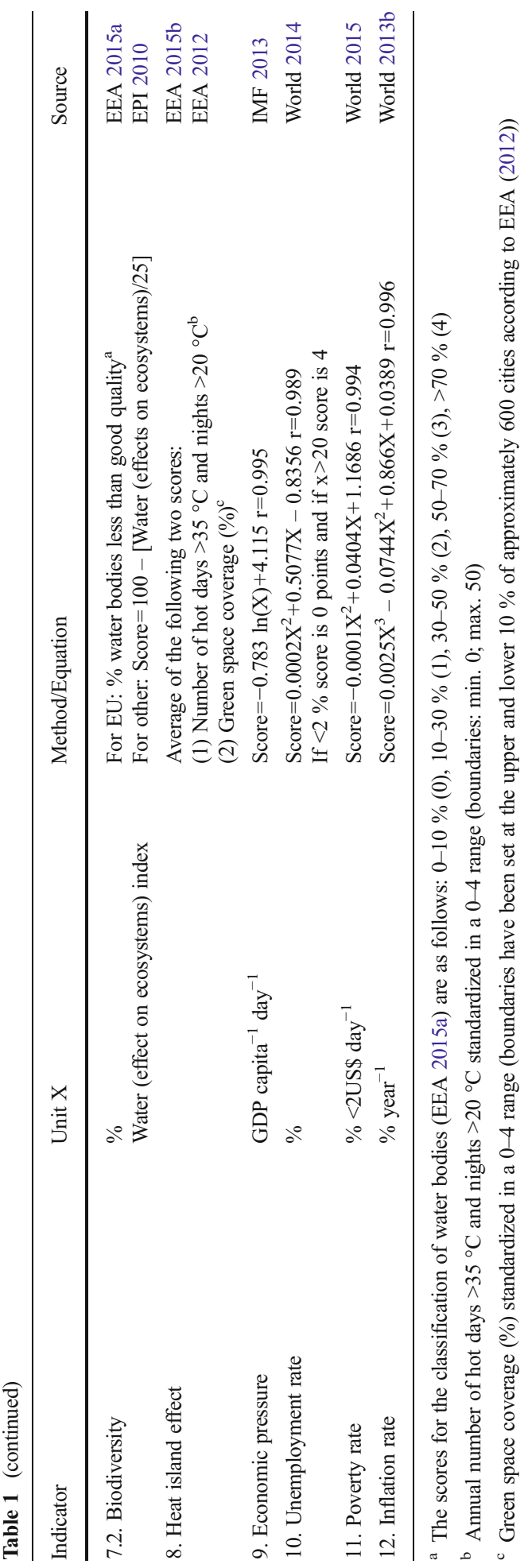



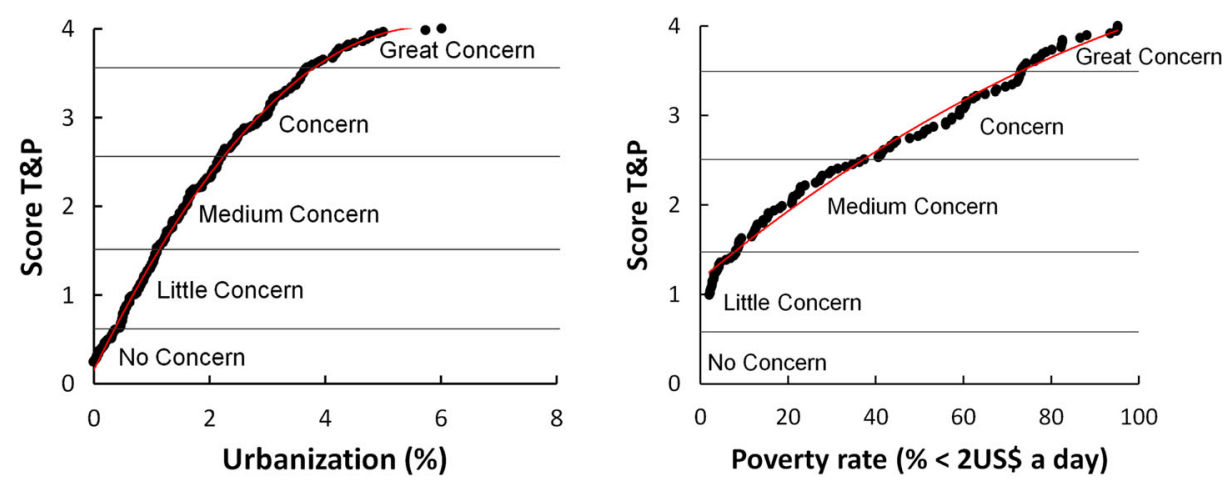

Fig. 2 Two examples of trends and pressure indicators developed in step 1 of this revision (Fig. 1). Left: urbanization rate (CIA 2014). Right: poverty rate (World Bank 2014). The urbanization and poverty rates of all available countries are ranked and subsequently linearly converted into scores of $0-4$ (y-axis). Based on this score, ordinal classes, expressed as 'degree of concern', are used. Table 1 provides the calculation method

questionable data reliability. In the current $\mathrm{CBF}$, the indicator surface water quality uses data from the water quality index (WQI) of the environmental performance index (EPI 2010). The WQI is the only global database of water quality for inland waters. However, insufficient spatial and temporal coverage of measurements, poor reporting and inconsistent sampling design, all posed data reliability problems (Srebotnjak et al. 2012). Therefore, the EPI stopped using the WQI after the year 2010 (EPI 2012).

A similar concern is the current indicator biodiversity, for which information is provided for member states of the European Union (EU), but this information is not available for non-EU countries (EEA 2014a). As an estimate for non-EU countries, the EPI water (effects on ecosystems) index has been used (EPI 2010). However, data reliability and the use of different databases appeared to be problematic (Emerson et al. 2010; Koop and Van Leeuwen 2015b). Moreover, both indices are national averages which lead to overestimations of urban water quality and biodiversity because cities are often large emitters of pollutants (Van Leeuwen 2013; Gessner et al. 2014).

Cities may have hardly any direct influence on the scores for surface water quality and biodiversity because of upstream pollution. Hence, the indicators water quality and biodiversity should focus on the city's own IWRM performance to prevent pollution. The coverage of secondary Waste Water Treatment (WWT) greatly determines the quality and biodiversity in urban waters because detrimental effects on aquatic species due to oxygen depletion are avoided. WWT removes at least $70 \%$ of the biological and $75 \%$ of the chemical oxygen demand (OECD 2013). Furthermore, the coverage of tertiary WWT avoids eutrophication by removing nitrogen and phosphorous, as well as other (microbiological) pollutants (OECD 2013). Secondary and tertiary WWT data are often available at the level of cities, frequently updated and widely used by international organizations (ISO 2014; UN Water 2014; OECD 2013; Siemens 2015; SOPAC 2004).

The scores for indicators 10 (nutrient recovery), 11 (energy recovery) and 12 (sewage sludge recycling) have been updated. These indicators reflect the reuse of wastewater as a fraction of the water that is passing the city's wastewater treatment plants; whereas the city's WWT service coverage is disregarded. Hence, a city that only treats a small fraction of its wastewater, but fully recycles the nutrients, sludge and applies full energy recovery from this small fraction, would receive a high score 
for these indicators while loads of potentially abstractable nutrients, sludge and energy actually flush away. In order to take all urban wastewater into account, the scores are therefore multiplied by the fraction of wastewater (F) that is actually treated at the WWT facilities (Eqs. 1, 2 and 3).

$$
\text { Score for nutrient recovery }=(\text { nutrient } \operatorname{recovery}(\%) * \mathrm{~F}) / 10
$$

$$
\text { Score for energy recovery }=(\text { energy recovery }(\%) * \mathrm{~F}) / 10
$$

Score for sewage sludge recycling $=($ sewage sludge recycling $(\%) * \mathrm{~F}) / 10$

\subsubsection{Public Participation}

The Voluntary Participation Index (VPI) is used for indicator 23 (public participation) and represents the average number of memberships in voluntary organizations as measured for EU-countries in 2003 (EFILWC 2006). We have updated this indicator by using the percentage of people involved in unpaid work (EFILWC 2012). For non-EU countries a best estimate is provided (Eq. 4) based on the high correlation with the World Bank indicator Rule of Law $(\mathrm{n}=27 ; \mathrm{r}=0.84 ; \mathrm{p}<0.0000001)$.

Public participationscore $=0.0657 *$ score for Rule of Law-2.2278

\subsubsection{Indicator Boundaries}

The indicators of the CBF are standardized according to the min-max method, by using percentages or by a self-assessment scoring method as explained in the City Blueprint questionnaire (EC 2015). The min-max standardization method is sensitive for outliers that may result in unrealistic scores and therefore indicator boundaries have been reviewed. For instance, indicator 16 (water system leakages) measures the leakage rate of the drinking water distribution system. The indicator boundaries for leakage have been set at 0 and $100 \%$, respectively. Consequently, $0 \%$ is equivalent to a completely leaking water distribution system which results in a low variance of this indicator. Therefore, the maximum boundary of water leakage has been arbitrarily reset at $50 \%$. The same holds for indicator 15 (average age sewer system), where the maximum age of the urban sewers has been lowered from 100 to 60 year. For large datasets $(n>100)$, the average of the lower and upper $10 \%$ have been used as minimum and maximum. This is done for indicator 4 (solid waste collected), 17 (operation cost recovery) and 18 (green space).

\subsubsection{Water Footprint Indicators}

Based on constructive criticism from local water authorities concerning the use of the Water Footprint (WF) concept (used in the former category water security), it has been decided to discontinue their use. The WF describes the total volume of water over the full supply chain 
that is needed to produce a product or that is used by a country (Hoekstra et al. 2009). Water imports and exports of a country are highly dependent on many social-economic processes and national and global trends on which the local water authorities have a negligible influence. Moreover, the indicator water scarcity and water self-sufficiency are largely determined by the total renewable water resource which is abundant or not, regardless of the interventions by local water authorities. In fact, temperature, rainfall, soil type, river course, etc., largely determine the total renewable water resources.

\subsubsection{Solid Waste}

Cities are prone to water pollution due to their highly efficient drainage systems that quickly collect and discharge polluted water. Cities are the largest source of plastic waste that enters the oceans via rivers and canals. About 280 million tonnes of plastics ends up in the oceans annually, where it photodegrades into small particles and affects marine ecosystems (Derraik 2002; Sigler 2014). The degradation of plastic waste in landfills is approximately 1 to $5 \%$ during 100 years (Bez et al. 1998). Urban solid waste treatment is therefore a key performanceoriented aspect that determines the water quality in cities, rivers and oceans. According to the European Commission (EC 2008), the priority order for waste reduction is waste prevention, reuse, recycling, recovery and disposal. Hence, indicator 4 (solid waste collected), 5 (solid waste recycled) and 6 (solid waste energy recovered) have been included.

\subsection{Step 3: Indicator Rearrangements and Aggregation Method}

The contribution of the indicators and categories to the BCI are currently highly variable. Indicators with low variances contribute less to the BCI. Moreover, the variances differ strongly and the number of indicators per category are not equal (Koop and Van Leeuwen 2015b). However, an equal contribution of each category and indicator is strived for. The final rearrangement of the indicators and categories is shown in Table 2. Currently, no particular penalty for unbalanced scores are given, and therefore the need to improve the achievements for low scoring indicators needs to be addressed (JRC 2014).

\subsubsection{Basic Water Services}

An indicator intra-correlation analysis revealed that the indicators safe sanitation, sufficient to drink and drinking water quality strongly correlate (Koop and Van Leeuwen 2015b). Access to proper drinking water and improved sanitation are basic water services which are united into a new category, i.e., category III (basic water services). The remaining indicators in the former category sanitation, all deal with wastewater treatment and the category has been renamed to 'wastewater treatment' (category IV; Table 2). This is in accordance with the ISO37120, which is a much broader urban indicator framework that also includes a 'water and sanitation' and 'wastewater' category (ISO 2014).

\subsubsection{Climate Robustness}

The correlation coefficient between the indicators climate commitment and adaptation measures is high $(\mathrm{r}=0.93)$. Given the similar ordinal assessment method, it is most 
Table 2 Overview of the performance indicators of the improved City Blueprint Framework (CBF) as described in step 2 and 3 of the revision (Fig. 1). Indicators in bold are new and indicators with adjusted scaling or new data bases are in italics. The other indicators have not been adjusted

I. Water quality

II. Solid waste treatment

III. Basic water services

IV. Wastewater treatment

V. Infrastructure

VI. Climate robustness

VII. Governance

\section{Secondary WWT}

2. Tertiary WWT

3. Groundwater quality

4. Solid waste collected

5. Solid waste recycled

6. Solid waste energy recovered

7. Access to drinking water

8. Access to sanitation

9. Drinking water quality

10. Nutrient recovery

11. Energy recovery

12. Sewage sludge recycling

13. WWT energy efficiency

14. Stormwater separation

15. Average age sewer

16. Water system leakages

17. Operation cost recovery

18. Green space

19. Climate adaptation

20. Drinking water consumption

21. Climate-robust buildings

22. Management and action plans

23. Public participation

24. Water efficiency measures

25. Attractiveness

likely that these indicators overlap. Furthermore, given the high correlations with indicators 19, 20, 22 and $23(\mathrm{r}>0.71)$, it is presumable that the indicator climate commitment is redundant and has therefore been removed (Koop and Van Leeuwen 2015b). Although climate change impacts are complex and ubiquitous, three climate vulnerabilities with particular reference to urban areas have been identified, i.e., UHI, water scarcity and flooding (EEA 2012). The UHI exacerbates heat waves in cities because the cooling effect of vegetation is replaced by surfaces sealed with concrete, asphalt and stone (EEA 2012). Green and blue areas store rainwater and evaporate this water, thereby mitigating heat waves and storm events. In addition, green and blue areas alleviate air pollution, increase the city's recreational value and reduce water polluted (Li et al. 2014; Jia et al. 2013; Jonker et al. 2014; Czemiel Berndtsson 2014). Therefore, the share of blue and green area (\%) is added as a new indicator in category VI (climate robustness), shown in Table 2. Climate change will also increase the urban vulnerability to water scarcity (EEA 2012). The domestic and industrial use of drinking water is an adequate indication of how cities combat water scarcity. Therefore indicator 20 (drinking water consumption) is also included in category VI (climate robustness) (Table 2). 


\subsubsection{Governance}

At this stage of the framework rearrangement, the former category biodiversity and attractiveness only includes indicator 25 (attractiveness), because the indicator biodiversity has previously been removed. Indicator 25 (attractiveness) measures the incorporation of bluegreen areas which is mainly the result of urban planning by local authorities, the local community and private companies (shops, factories, restaurants, bars etc.) who want to shape an attractive place to live. The relation with governance is also indicated by the correlations with the indicator 22 (management and action plans) ( $\mathrm{r}=0.53), 23$ (public participation) $(\mathrm{r}=0.61)$ and 24 (water efficiency measures) $(\mathrm{r}=0.74)$. Water efficiency measures assesses to what extent water efficiency measures are applied. Because correlated indicators 22, 23, 24 and 25 all assess how local authorities manage water issues, these indicators have been united into category VII (governance).

\subsubsection{Infrastructure}

The former category infrastructure is only poorly accounted for given the large maintenance cost and large global investment deficit in water infrastructure (AWWA 2001; Cashman and Ashley 2008). Therefore indicator 16 (water system leakages) has been added because it is suitable to represent the maintenance of the drinking water infrastructure. In contrast with data on total investments in water infrastructure, data of operation costs and revenues of drinking water and sanitary services is often available (IBNET 2015; OECD 2010). The ratio of the total yearly operating revenues divided by the operating costs of drinking water and sanitation services is an important indicator of the financial state of the local water authorities and their ability to make the necessary investments in infrastructure (OECD 2015). Hence, indicator 17 (operation cost recovery) is added to strengthen category V (infrastructure), given in Table 2.

\subsubsection{Aggregation Method}

For composite indices, issues of weighting and aggregation are sensitive and subjective (EPI 2010). It should be recognized that assigning explicit weightings, by definition, represents only one viewpoint. Therefore, no indicator or category weightings are applied. Moreover, the implicit weighting, due to correlations and/or differences in variances are addressed before the indicators are aggregated.

Most frequently used aggregation methods are the arithmetic and geometric mean. The arithmetic mean gives no particular penalty for unbalanced scores, and consequently does not address the urgent need to improve achievements for the lowest scores (JRC 2014). However, it is essential to regard water management in an integrative way, e.g., increasing access to sanitation greatly improves human hygiene but without adequate investments in WWT, this leads to a strong emission increase in hazardous pollutants and nutrients. Hence, a high score for access to sanitation should not fully compensate a low score for WWT coverage (Ligtvoet et al. 2014).

Since a geometric mean can be defined as the $\mathrm{n}^{\text {th }}$ root of the product of $\mathrm{n}$ numbers or as the anti-log of the sum of $\log$ s divided by the number of samples and the log zero (0) is not defined, the calculation of the geometric mean method requires strictly positive values. It is therefore chosen to re-standardize the indicators to a 1-11 score, aggregate the indicators with 
the geometric mean and finally subtract 1 point from this score. In this way, balanced indicator performances are rewarded.

\subsection{Examples}

For all 45 cities data have been gathered for the analyses of their TPF and improved CBF. In this section examples of only three cities are presented, i.e., Dar es Salaam, Melbourne and Amsterdam. The TPF is shown in Table 3. The overall Trends and Pressure Index (TPI) for Dar es Salaam, Melbourne and Amsterdam are 2.7, 1.1 and 1.2 respectively. The improved City Blueprints for these cities are shown in Fig. 3. The new BCI for Dar es Salaam, Melbourne and Amsterdam are 1.3, 5.4 and 8.3 respectively. The performance ranking of these cities is shown for each category (Fig. 4).

\section{Discussion}

\subsection{City Blueprint Improvements}

We have developed two separated indicator frameworks that embody the distinction between trends and pressures (TPF) and IWRM performance of a city (CBF). In the TPF only indicators that are of concern or great concern ( 3 or 4 points) are explicitly communicated to the stakeholders (Table 3). The CBF is essential to show the potential gain possible by sharing knowledge, experiences and best practices amongst cities. Moreover, it more accurately depicts the own activities and efforts of cities to improve the sustainability of their IWRM and how they can alleviate environmental pressures such as emissions of poorly treated wastewater and solid waste. The TPF provides a wider context, which is key in obtaining insight into the limitations and windows of opportunities to improve urban IWRM. Finally, the categories of the 45 cities are averaged and ranked

Table 3 Trends and Pressures Framework (TPF) of Dar es Salaam, Melbourne and Amsterdam with their concern scores: 0 (no concern), 1 (little concern), 2 (medium concern), 3 (concern), and 4 (great concern)

\begin{tabular}{lllll}
\hline & & Dar es Salaam & Melbourne & Amsterdam \\
\hline \multirow{2}{*}{ Social } & 1. Urbanization rate & 4 & 1 & 1 \\
& 2. Burden of disease & 3 & 1 & 0 \\
& 3. Education rate & 3 & 0 & 1 \\
Environmental & 4. Political instability & 2 & 1 & 1 \\
& 5. Water scarcity & 2 & 1 & 1 \\
& 6. Flood risk & 3 & 2 & 2 \\
Financial & 7. Water quality & 1 & 2 & 1 \\
& 8. Heat risk & 3 & 4 & 1 \\
9. Economic pressure & 4 & 0 & 1 \\
10. Unemployment rate & 1 & 1 & 1 \\
\hline
\end{tabular}



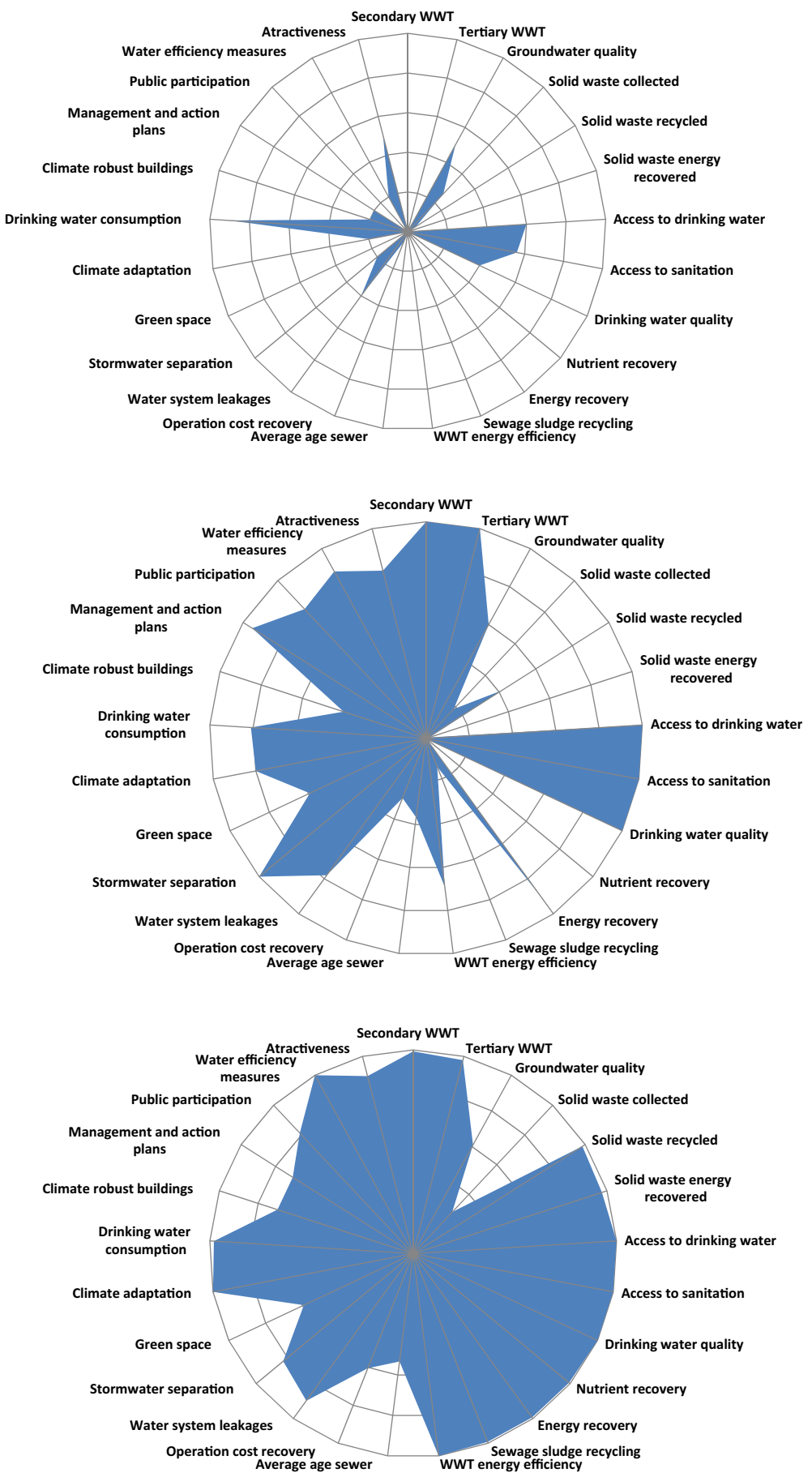

Fig. 3 Spider diagram application of the improved performance framework (Fig. 1). Examples of three spider diagrams based on 25 performance indicators for Dar es Salaam (top), Melbourne (centre) and Amsterdam (bottom). The geometric mean of the indicators, i.e., the $\mathrm{BCI}$, are 1.3, 5.4 and 8.3 , respectively 


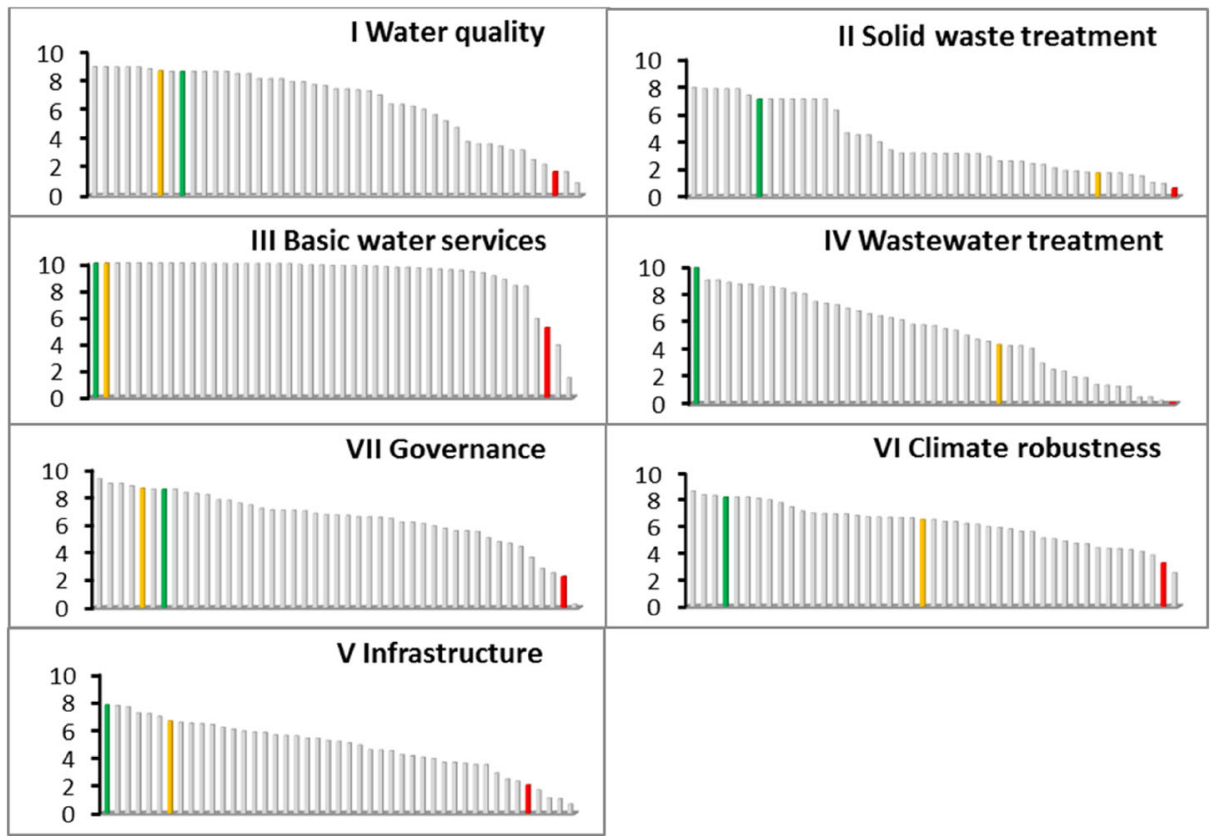

Fig. 4 Category ranking of the City Blueprints of Dar es Salaam (red), Melbourne (orange) and Amsterdam (green). The arithmetic average of the indicator scores for each of the seven categories (Table 2) are ranked from high to low for each of the 45 municipalities and regions. This ranking is part of the application of the performance framework (Fig. 1)

in order to provide a quick overview of potential improvements compared to other cities (Fig. 4). These simple graphical representations allow for a quick overview of cities on their path to become water-wise and climate prove.

\subsection{Limitations}

Only publicly available data is added to this improved CBF in order to promote transparency, and to reduce time and costs. City scale data concerning urban IWRM appeared to be particularly scarce. In fact, this information is often available, but publicly inaccessible which hampers city-to-city learning (EEA 2014b). Moreover, existing urban water-related indicators are often not standardized, consistent, or comparable over time and between cities (ISO 2014). For a considerable number of indicators national data are used because local data is not publicly available for all cities. This limits the accuracy of city assessments, especially in large countries with high regional variety.

Basic statistics obtained from the 45 cities have been used to reconstruct the CBF and to arrive at an approximately proportional contribution of all indicators and categories. However, the 45 cities that are used for this statistical analysis have a distribution bias as most cities are located in North-West Europe and are therefore not representative for the global urban challenges. This is a limitation of our work. Hence, it should be taken into account that the actual variance of the indicators may differ from the output of cities that have been analysed. For instance, the variance of 
category 3 (basic water services) and 7 (governance) is expected to be larger if the cities would really represent a global sample, i.e., if cities from developing countries would not be underrepresented.

\subsubsection{Indicator Limitations}

The data for the baseline assessment proposed in this paper is gathered by means of a questionnaire (EC 2015) and by using publicly available data. In order to include a large number of cities of different size and geography, the indicator framework is limited by the information that was available. Hence, the set of indicators can and should be extended for some cities. Public data concerning flood risks appeared to be particularly sparse. Information on urban flood vulnerability is available, i.e., vulnerability to river peaks and sea level rise (Jongman et al. 2014; EEA 2012). However, these data do not represent flood protection performances. Hence, these indicators are included in the TPF. Ideally, a flood return interval is used to quantify the performance of flood defence. However, flood return intervals are not consistently reported worldwide, let alone, calculated in comparable manner.

The percentage of uncollected solid waste is inconsistently reported. Only for a very few cities, it was more than zero, preventing it to become a suitable comparative indicator. However, uncollected solid waste can strongly contribute to the release of a variety of pollutants such as heavy metals, persistent bio-accumulative chemicals, pesticides, pharmaceuticals and plastic (Katsanevakis 2011). However, efforts to reduce water polluting activities such as landfilling and solid waste production are explicitly included.

Another major cause of urban water pollution is stormwater runoff. This pollution pathway is related to traffic intensity and uncollected solid waste (Czemiel Berndtsson 2014; Revitt et al. 2014). Urban soil permeability or the use of best practices to reduce or filter stormwater runoff, e.g., by biofilters, infiltration ponds or bioswales, may be insufficiently addressed in the CBF due to limited data availability on soil permeability. Only indicator 18 (green space) and 19 (climate adaptation) implicitly address these issues. Hence, a supplementary indicator that assesses the application of measures to decrease and filter stormwater runoff could be added.

The min-max method can be sensitive for extreme outliers that may disrupt the scoring. Therefore the average of the lower and upper $10 \%$ from a large data set $(\mathrm{n}>100)$ is taken as the minimum and maximum for indicators 4 (solid waste collection), 17 (operation cost recovery) and 18 (green space). However, for drinking water consumption this was hindered because there was no large dataset that included residential, commercial, industrial and public purposes. Often only domestic water consumption data is provided which represents only $10 \%$ of the total drinking water consumption in the EU (ISO 2014). Likewise, indicator 15 (average age sewer) is prone for outliers because minimum and maximum numbers are taken from a limited dataset.

Data coverage of the selected set of indicators is high. Only the operation cost recovery (ratio) of Helsinki and data according to the EEA (2012) assessment method for indicator 18 (green space) were not available for non-EU cities. In most cases a realistic default value of $20 \%$ green space is taken (e.g., for Ho Chi Minh City and Istanbul) and only for Melbourne we arbitrarily set this score equal to that of Amsterdam. Finally, the operation cost recovery for Helsinki has been arbitrarily set at 1 , as data have not been provided. 


\subsubsection{Water Infrastructure Investment Deficit}

Upgrading of water infrastructure is crucial for water security in cities (OECD 2015). Water infrastructure investment requirements are already high in developed countries (yearly 0.35$1.2 \%$ of GDP) and even higher for developing countries (yearly $0.71-6.30 \%$ of GDP) (Cashman and Ashley 2008). Hence, the state of the water infrastructure network (indicator 15 average age sewer) is decisive for the city's financial performance.

As an indication of the maintenance of the sewer system in a city, we have divided the average by an assumed sewer lifespan. This is an inaccurate approximation since local circumstances that determine the sewer lifespan are not incorporated. A first improvement could be to determine a site-specific maximum sewer lifespan and compare this with the current site-specific average age. A more advanced approach would be to calculate the yearly sewer maintenance investment requirement (Equation 5) as proposed by Prof. Dr. Bosseler (personal communication). The infrastructure lifespan and system asset value should be calculated for each city. By using equation (5), an annual investment can be calculated that should be reserved for long-term infrastructure maintenance. The actual investment in infrastructure can be scored as a fraction of this annual investment requirement.

$$
\text { Investment requirements }(\epsilon / \text { year })=\frac{\text { System Asset Value }(\epsilon)}{\text { Lifespan }(\text { years })}
$$

\section{Conclusions}

The goal of this study is a methodological review of the City Blueprint indicator framework to improve the assessment of the sustainability of IWRM in cities (Fig. 1). The results of the application of this improved method has been reported in this journal (Koop and Van Leeuwen 2015a). This revision was necessary to better emphasize cities' opportunities to envision, develop and implement stepwise measures to transform towards water-wise or water sensitive cities. The following changes have been made:

1. A distinction between descriptive and performance-oriented indicators has been made by developing a Trends and Pressures Framework (TPF; on which the city's IWRM has a negligible influence) and improving the city-level IWRM performance framework, i.e., the City Blueprint Framework (CBF).

2. The TPF includes the following social, environmental and financial indicators: urbanization rate, burden of disease, education rate, political instability, water scarcity, flood risk, water quality, heat risk, economic pressure, unemployment rate, poverty rate and inflation rate. The data are publicly available (Table 1$)$.

3. We distinguish 5 ordinal classes, varying from no concern to great concern, for each of these 12 TPF indicators.

4. In the revised CBF, seven indicators have been added, i.e., secondary and tertiary wastewater treatment, operation cost recovery, green space and three indicators concerning solid waste treatment (Table 2).

5. Adjusted scaling or new databases are used for the following CBF indicators: nutrient recovery, energy recovery, sewage sludge recycling, average age sewer, water system leakages and public participation (Table 2). 
6. The geometric aggregation method has been chosen to calculate the Blue City Index for the 25 indicators of the CBF.

7. We have applied this new CBF, TPF and BCI to 45 cities in 27 countries (Koop and Van Leeuwen 2015a).

8. The focus on performance will enhance city-to-city learning, i.e., sharing of knowledge, experiences and best practices between cities. This is the ultimate goal of our EIP Water Action Group (EC 2015) as the need to improve IWRM in cities is crucial and the time window to do this, is closing rapidly (OECD 2015; Van Leeuwen 2013).

Acknowledgments We would like to thank Prof. Dr. Bosseler (Institute for Underground Infrastructure, Gelsenkirchen, Germany) for his advice on water infrastructure investment deficits. The City Blueprint Action Group is part of the governance activity of the European Innovation Partnership on Water of the European Commission, coordinated by both Dr. Richard Elelman of Fundació CTM Centre Tecnològic and NETWERC H2O (Manresa, Spain) and Prof. Dr. Kees Van Leeuwen of KWR Watercycle Research Institute. The European Commission is acknowledged for the support of our City Blueprint action and for the BlueSCities project in H2020-Water under Grant Agreement No. 642354.

Open Access This article is distributed under the terms of the Creative Commons Attribution 4.0 International License (http://creativecommons.org/licenses/by/4.0/), which permits unrestricted use, distribution, and reproduction in any medium, provided you give appropriate credit to the original author(s) and the source, provide a link to the Creative Commons license, and indicate if changes were made.

\section{References}

AWWA (2001) American water works association. Reinvesting in drinking water infrastructure. Government Affair Office, New York

Bez J, Heyde M, Goldhan G (1998) Waste treatment in product specific life cycle inventories. An approach of material-related modelling. Part II: Sanitary landfill. Int J Life Cycle Ass 3:100-105

Brown R, Ashley R, Farrelly M (2011) Political and professional agency entrapment: an agenda for urban water research. Water Resour Manag 25:4037-4050

Cashman A, Ashley R (2008) Costing the long-term demand for water sector infrastructure. Foresight 10:9-26

CIA (2014) Central Intelligence Agency: The World Factbook. Urbanization https://www.cia.gov/library/ publications/the-world-factbook/fields/2212.html Accessed 18 March 2015

Czemiel Berndtsson J (2014) Storm water quality of first flush urban runoff in relation to different traffic characteristics. Urban Water J 11:284-296

Derraik JGB (2002) The pollution of the marine environment by plastic debris: a review. Mar Pollut Bull 44:842852

EC (2008) European Commission. Directive 2008/98/EC of the European parliament and of the council on waste and repealing certain directives - Appendix II, 19 November 2008

EC (2015) European Commission: European Innovation Partnership on Water. Brussels, Belgium. http://www. eip-water.eu/City_Blueprints Accessed 12 March 2015

EEA (2012) European environment agency. Urban adaptation to climate change in Europe. Challenges and opportunities for cities together with supportive national and European policies. Synthesis, Copenhagen, Denmark

EEA (2014a) European Environmental Agency: Water Framework Directive and monitoring http://www.eea. europa.eu/themes/water/status-and-monitoring/water-framework-directive-and-monitoring Accessed 29 January 2015

EEA (2014b) European environmental agency: performance of water utilities beyond compliance. Sharing knowledge bases to support environmental and resource-efficiency policies and technical improvements. Technical report No 5/2014, Copenhagen, Denmark

EEA (2015a) European environmental agency: Percent of classified water bodies in less than good ecological status of potential. http://www.eea.europa.eu/data-and-maps/figures/proportion-ofclassified-surface-water/proportion-of-classified-surface-water/image_original Accessed 8 January 2015 
EEA (2015b) European environmental agency: Urban adaptation to climate change. Annex II. City data sensitivity. http://www.eea.europa.eu/data-and-maps/figures/mean-soil-sealing-in-european Accessed 19 January 2015

EFILWC (2006) European foundation for the improvement of living and working conditions. First European Quality of life survey: Participation in civil society, Dublin

EFILWC (2012) European foundation for the improvement of living and working conditions. Quality of life in Europe: Impact of the crisis, Luxembourg

Emerson JDC, Esty MA, Levy CH, Kim V, Mara ADE, Sherbinin E, Srebotnjak T (2010) 2010 Environmental performance index. Yale Center for Environmental Law and Policy, New Haven

EPI (2010) Environmental performance index: http://www.ciesin.columbia.edu/repository/epi/data/2010EPI country_profiles.pdf Accessed 19 January 2015

EPI (2012) Environmental Performance Index: Environmental Performance Index and Pilot Trend Environmental Performance Index. http://epi.yale.edu/files/2012 epi_report.pdf Accessed 21 February 2015

FAO (2015) Food and Agriculture Organization of the United Nations: AQUASTAT database. http://www.fao. org/nr/water/aquastat/data/query/index.html;jsessionid=B022D1C2732DF571D2A384B57E0128D6 Accessed 19 January 2015

Gessner MO, Hinkelmann R, Nützmann G, Jekel M, Singer G, Lewandowski J, Nehls T, Barjenbruch M (2014) Urban water interfaces. J Hydrol 514:226-232

Gill S, Handley J, Ennos A, Pauleit S (2007) Adapting cities for climate change: the role of the green infrastructure. Build Environ 1:115-133

Hoekstra AY, Wiedman TO (2014) Humanity's unsustainable environmental footprint. Science 344:1114-1117

Hoekstra AY, Chapagain AK, Aldaya MM, Mekonnen MM (2009) The water footprint manual. Setting the global standard, 2009. Water Footprint Network, Enschede

IBNET (2015) The International Benchmarking Network for Water and Sanitation Utilities: Search by country http://www.ib-net.org/en/production/?action=country Accessed 10 March 2015

Iglesias A, Garrote L, Flores F, Moneo M (2007) Challenges to manage the risk of water scarcity and climate change in the Mediterranean. Water Resour Manag 21:775-788

Igrac (2010) International Groundwater Resources Assessment Center: Groundwater Development stress http:// www.unesco.org/new/fileadmin/MULTIMEDIA/HQ/SC/temp/wwap pdf/Groundwater development stress_GDS.pdf Accessed 21 January 2015

IMF (2013) International Monetary Fund: World economic outlook database, April 2013 http://www.imf.org/ external/pubs/ft/weo/2013/01/weodata/index.aspx Accessed 19 January 2015

IPCC (2013) International panel on Climate Change: Climate change 2013. The Physical science basis. Contribution of Working Group I to the Fifth Assessment Report of the Intergovernmental Panel on Climate Change [Stocker TF, Qin D, Plattner GK, Tignor M, Allen SK, Boschung J, Nauels A, Xia Y, Bex V and Midgley PM (eds.)]. Cambridge University Press, Cambridge, United Kingdom and New York, NY, USA

ISO (2014) International standards organization. Sustainable development of communities. Indicators for city services and quality of life. ISO, Geneva

Jia B, Wang C, Qiu E, Qie G (2013) The status and trend on the urban tree canopy research. Acta Ecol Sin 33:23-32

Johnson T (2013) Hurricane Sandy leaves state with \$2.6B tab for water infrastructure. http://www.njspotlight. com/stories/13/04/09/hurricane-sandy-leaves-state-with-2-6b-tab-for-water-infrastructure/ Accessed 27 July 2015

Jongman B, Hochrainer-Stigler S, Feyen L, Aerts JCJH, Mechler R, Botzen WJW, Bouwer LM, Pflug G, Rojas R, Ward PJ (2014) Increasing stress on disaster-risk finance due to large floods. Nat Clim Change 4:264-268

Jonker MFJ, Van Lenthe F, Donkers B, Mackenbach JP, Burdorf A (2014) The effect of urban green on smallarea (healthy) life expectancy. J Epidemiol Community Health 68:999-1002

JRC (2014) Joint Research Center: Climate Impacts in Europe The JRC PESETA II Project. Report EUR 26586EN, Seville http://publications.jrc.ec.europa.eu/repository/handle/111111111/31757 Accessed 17 March 2015

Katsanevakis S (2011) Marine debris, a growing problem: sources, distribution, composition, and impacts. Nova, New York

Koop SHA, and Van Leeuwen CJ (2015a) Application of the improved City Blueprint Framework in 45 municipalities and regions. Water Resour Manag 29:4629-4647

Koop SHA, and Van Leeuwen CJ (2015b) Towards sustainable water resources management: Improving the city blueprint framework. Report KWR 2015.025. KWR Watercycle Research Institute, Nieuwegein, the Netherlands. http://www.eip-water.eu/City_Blueprints Accessed 4 August 2015 
Leonardsen L (2012) Financing adaptation in Copenhagen http://resilient-cities.iclei.org/fileadmin/sites/resilientcities/files/Webinar_Series/Webinar_Presentations/Leonardsen_financing_adaptation_in_Copenhagen ICLEI_sept_2012.pd̄f Accessed 12 May 2015

Li F, Wang RS, Z̄hao D (2014) Urban ecological infrastructure based on ecosystem services: status, problems and perspectives. Acta Ecol Sin 34:190-200

Ligtvoet W, Hilderink H, Bouwman A, Puijenbroek P, Lucas P, Witmer M (2014) Towards a world of cities in 2050. An outlook on water-related challenges. Background report to the UN-Habitat Global Report. PBL Netherlands Environmental Assessment Agency

McKinsey (2013) Infrastructure productivity: How to save \$1 trillion a year. McKinsey \& Company

Mori K, Yamashita T (2015) Methodological framework of sustainability assessment in city sustainability index (CSI): a concept of constraint and maximisation indicators. Habitat Int 45:10-14

Nilsen V, Lier JA, Bjerkholt J, Lindholm OG (2011) Analysing urban floods and combined sewer overflows in a changing climate. J WateR Clim Change 2:260-271

OECD (2004) Organization for economic communication and development: OECD key environmental indicators, Paris, France http://www.oecd.org/environment/indicators-modelling-outlooks/31558547.pdf Accessed 9 March 2015

OECD (2010) Organization for Economic Co-operation and Development: Pricing water resources and water and sanitation services http://browse.oecdbookshop.org/oecd/pdfs/product/9710041e.pdf Accessed 10 March 2015

OECD (2013) Organization for Economic Co-operation and Development: Environment at a glance 2013. OECD indicators. OECD Publishing. DOI: 10.1787/9789264185715-en http:/www.oecd-ilibrary.org/ environment/environment-at-a-glance-2013_9789264185715-en Accessed 7 March 2015

OECD (2015) Organization for economic co-operation and development: water and cities. Ensuring sustainable futures. OECD studies on water. OECD Publishing. doi:10.1787/9789264230149-en

Philip R, Anton B, van der Steen P (2011) SWITCH training kit. Integrated urban water management in the city of the future. Module 1. Strategic planning, ICLEI, Freiburg, Germany. http://www.switchtraining.eu/ Accessed 10 March 2015

Revitt DM, Lundy L, Coulon F, Fairley M (2014) The sources, impact and management of car park runoff pollution: a review. J Environ Manage 146:552-567

Short MD, Peirson WL, Peters GM, Cox RJ (2012) Managing adaptation of urban water systems in a changing climate. Water Resour Manag 26:1953-1981

Shuster WD, Bonta J, Thurston H, Warnemuende E, Smith DR (2005) Impacts of impervious surface on watershed hydrology: a review. Urban Water J 2:263-275

Siemens (2015) Green city index. http://www.siemens.com/entry/cc/en/greencityindex.htm Accessed 2 April 2015

Sigler M (2014) The effects of plastic pollution on aquatic wildlife: Current situations and future solutions. Water Air Soil Poll 225

SOPAC (2004) Applied Geoscience and Technology division of Secretariat of the Pacific Community: Environmental Vulnerability Index http://www.sopac.org/index.php/environmental-vulnerability-index Accessed 25 March 2015

Srebotnjak T, Carr GDE, Sherbinin A, Rickwood C (2012) A global water quality index and hot-deck imputation of missing data. Ecol Indic 17:108-119

UN (2014) United Nations. World urbanization prospect. The revision 2014. Highlights, New York

UNEP (2013) United Nations Environment programme. City-level decoupling. Urban resource flows and the governance of infrastructure transitions. A Report of the Working Group on Cities of the International Resource Panel. Swilling M, Robinson B, Marvin S, Hodson M. Nairobi, Kenia

UN Water (2014) United Nations Water: Set of Key Indicators for the Water Sector. http://www.unwater.org/ activities/task-forces/indicators/key-indicators/en/ Accessed 19 March 2015

Van Leeuwen CJ (2013) City blueprints: baseline assessments of sustainable water management in 11 cities of the future. Water Resour Manag 27:5191-5206

Van Leeuwen CJ, Sjerps R (2015) Istanbul: the challenges of integrated water resources management in Europa's megacity. Environ Dev Sustain. doi:10.1007/s10668-015-9636-z

Van Leeuwen CJ, Frijns J, Van Wezel A, Van De Ven FHM (2012) City blueprints: 24 indicators to assess the sustainability of the urban water cycle. Water Resour Manag 26:2177-2197

WHO (2014) World Health Organization: Burden of disease. Age-standardized disability-adjusted life year DALY- rates per 100000 (population): $2012 \mathrm{http}: / /$ gamapserver.who.int/gho/interactive_charts/mbd/as daly_rates/atlas.html Accessed 9 January 2015

World Bank (2012) Primary completion rate, total (\% of relevant age group) http://data.worldbank.org/indicator/ SE.PRM.CMPT.ZS/countries/1W-AO?display=default Accessed 13 January 2015 
World Bank (2013a) Worldwide Governance Indicators http://info.worldbank.org/governance/wgi/index. aspx\#faq. Accessed 12 January 2015

World Bank (2013b) Inflation, costumers price (annual \%) http://data.worldbank.org/indicator/FP.CPI.TOTL.ZG. Accessed 19 January 2015

World Bank (2014) Unemployment total (\% of total labor force) (modelled ILO estimate) http://data.worldbank. org/indicator/SL.UEM.TOTL.ZS Accessed 19 January 2015

World Bank (2015) Poverty gap at \$2 a day (PPP) (\%) http://data.worldbank.org/indicator/SI.POV.GAP2/ countries/1W?display=default Accessed 12 February 2015

WRG (2009) 2030 Water resources group. Charting our water future. Economic frameworks to inform decisionmaking, West Perth

WRI (2013) World Resources Institute. Aqueduct metadata document. Aqueduct global maps 2.0. http://www. wri.org/sites/default/files/pdf/aqueduct_metadata_global.pdf Accessed 15 May 2015

WWDR (2006) World Water Development Report: Water a shared responsibility. Section 2: Changing Natural Systems. The state of the Resource http://www.unesco.org/bpi/wwap/press/pdf/wwdr2_chapter_4.pdf Accessed 25 March 2015 